\title{
Correlation between endometrial thickening and histopathology findings in postmenopausal women
}

Fernanda Vilela, Ana Edral, Rita Martins, Amália Pacheco, Maria Carmo Cruz, Ana Casquilho

\section{Introduction}

Ultrasound measurement of endometrial thickness is a non-invasive diagnostic toll for assessment of endometrial pathology in menopausal women, asymptomatic or with vaginal bleeding. Thickened endometrium is an indication for an invasive evaluation as endometrial sampling or hysteroscopy.

The cut-off value of endometrial thickness that should warrant an endometrial study is not consensual, varying from 3 to $5 \mathrm{~mm}$. Most studies suggest that transvaginal ultrasound is an effective first line exam for endometrium evaluation in postmenopausal women, however it cannot substitute endometrial sampling.

Aim of the study: To correlate endometrial thickening with histopathology findings and understand the diagnostic value of ultrasound endometrial thickness measurement in predicting endometrial pathology in postmenopausal women in our hospital.

\section{Results}

Postmenopausal Women

Gynaecology appointment

Average age: 66,7 years

Average menopause age: 50,2 years

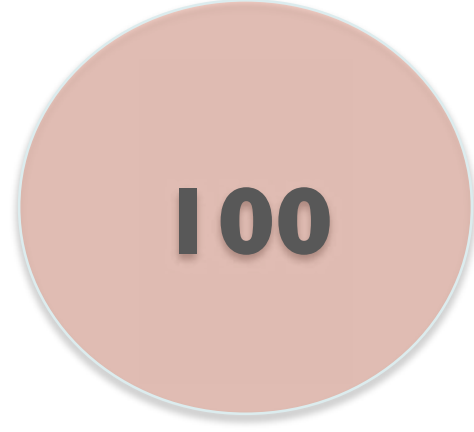

$+2$

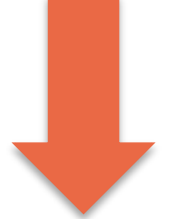

72\% Vaginal Bleeding

\section{Ultrasound}

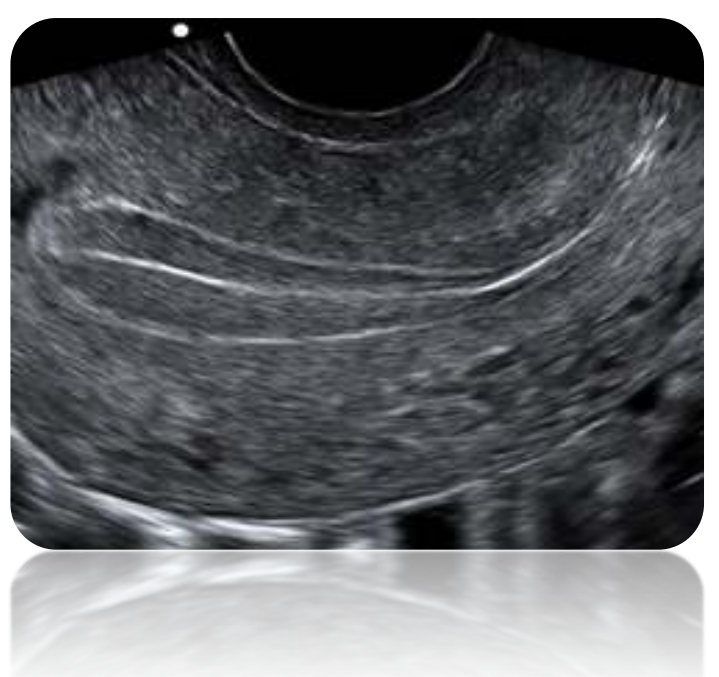

Average endometrial thickening

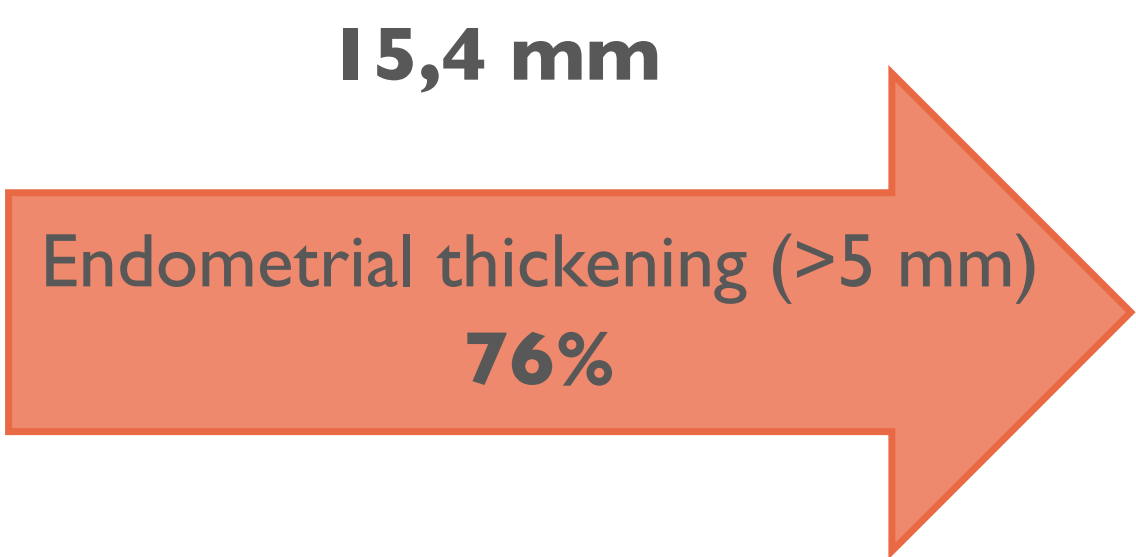

\begin{tabular}{ccc}
\hline Anatomo-pathology & & $\%$ \\
\hline Insuficient material & 11 & 16,9 \\
Normal & 14 & 21,5 \\
Polyp & 17 & 26,2 \\
hyperplasia without atypia & 18 & 27,7 \\
hyperplasia with atypia & 2 & 3,1 \\
\hline Endometrial carcinoma & 3 & 4,6 \\
\hline
\end{tabular}

- $26,2 \%$ of women with endometrial thickening had polyps $\rightarrow$ reduces the specificity of ultrasound;

- Average endometrial thickening was superior $(16,7$ vs $14,25 \mathrm{~mm})$ in woman with malignant and premalignant lesions;

- $91 \%$ of women with endometrial pathology had symptoms $\rightarrow$ all women with endometrial carcinoma had vaginal bleeding;

\section{Conclusion}

Our study found that endometrial thickening tends to correlate with endometrial pathology, however ultrasound measurement alone is not a good predictor of malignant and premalignant lesions, so it is required further invasive diagnostic testing.

Future perspectives of our work are to expand this sample and draw ROC curves to determine the cut-off value of endometrial thickening at our population and adjust our clinical practice. 